\title{
Sobre as mulheres ${ }^{(1)}$
}

\author{
Denis Diderot
}

Traduçăo de J. GUINSBURG

Eu amo Thomas ${ }^{(2)}$; respeito a altivez de sua alma e a nobreza de seu caráter: $\hat{e}$ um homem de muito esplrito; ế um homem de bern; năo ế pois um homem comum. A julgar por sua Dissertação sobre as mulheres, ele năo experimentou suficienternente uma paixăo que eu tomo muito mais pelas penas de que nos consola do que pelos prazeres que nos proporciona. Ele pensou muito, porém năo sentiu bastante. Sua cabeça se atormentou, mas o coraçăo permaneceu tranqüilio. Eu teria escrito com menos imparcialidade e sabedoria; mas eu me teria ocupado com mais interesse e calor do único ser da natureza que nos dá sentimento por sentimento, e que é feliz com a ventura que nos faz. Cinco ou seis páginas de verve espalhadas por seu trabalho romperiam a continuidade de suas observaçठes delicadas e converte-lo-iam numa obra encantadora. Mas ele quis que seu livro nẫo fosse de nenhum sexo; e infelizmente conseguiu isto bem demais. É um hermafrodita, que năo tem nem o nervo do homem, nem a brandura da mulher. Entretanto, poucos de nossos escritores atuais seriam capazes de um trabalho onde se observam erudiçăo, razăo, finu$\mathrm{ra}$, estilo e harmonia; mas năo variedade suficiente, essa flexibilidade capaz de prestar-se à infinita diversidade de um ser extremo na sua força e na sua fraqueza, que à vista de um sorriso ou de uma aranha faz cair em sincope, e que sabe às vezes afrontar os maiores terrores da vida. É sobretudo na paixăo do amor, nos acessos do ciúme, nos arrebatamentos da ternura maternal, nos instantes da superstiçăo, na maneira como partilham das emoçరెes epidêmicas e populares, que as mulheres espantam, belas como os serafins de Klopstock, terrfveis como os diabos de Milton. Vi o amor, o ciưme, a superstiçăo, a cólera, levados nas mulheres a um ponto que o homem nunca experimenta. O contraste dos movimentos violentos com a doçura de seus traços as torna hediondas; săo com isso mais desfiguradas. As distraçరes de uma vida ocupada e contenciosa rompem nossas paixठes. A mulher choca as suas: é um ponto fixo, sobre o qual a sua ociosidade ou a frivolidade de suas funçరes mantém o olhar incessantemente pregado. Esse ponto se estende desmesuradamente; $e$, para tornar-se louca, faltaria à mulher apaixonada apenas a inteira solidăo que ela procura. A submissăo a um senhor que the desapraz ê para ela um suplifcio. Vi uma mulher honesta tremer de horror à aproximaçăo do esposo; vi-a mergulhar no banho, e năo se julgar jamais suficientemente lavada da mácula do dever. Tal espécie de repugnância nos ế quase desconhecida. Nosso Orgăo é mais indulgente. Muitas mulheres morrem sem haver experimentado o extremo da voluptuosidade. Esta sensaçăo, que eu consideraria de bom grado como uma epilepsia passageira, é rara para elas, e năo deixa nunca de vir quando nós a chamamos. A suprema felicidade lhes foge entre os braços do homem que adoram. NOs a encontramos ao lado de uma mulher complacente que nos desagrada. Menos senhoras de seus sentidos do que nós, a recompensa destes é para elas menos rápida è menos segura. Centenas de vezes sua expectativa é enganada. Organizadas bem ao contrário a nós, o móvel que solicita nelas a voluptuosidade é tấo delicado, $\theta$ a sua fonte fica tăo afastada, que năo é extraordinário que ela nắo venha ou se extravie. Se ouvis uma mulher dizer mal do amor, e um homem de letras depreciar a consideraçăo pública, falai de uma que seus encantos passam e, de outro, que seu talento se perde. Nunca um homem sentou-se, em Delfo, sobre o sagrado tripé. O papel de Pfita convém apenas à mulher. So uma cabeça de mulher pode exaltar-se a ponto de pressentir seriamente a aproximaçăo de um

1 Este texto de Diderot apareceu como resenha crfica do livro de Thomas, na Correpondence de Grimm.

2 Autor de multos Eloges, Antoine-Loonard Thomas (1732-1785) fol membro da Academia Francesa. 
deus, de agitar-se, de descabelar-se, de espumar, de gritar: "Eu o sinto, eu sinto, ei-lo, o deus", e de encontrar o seu verdadeiro discurso. Um solitário(3), ardendo em suas idéias assim como em suas expressðes, dizia aos heresiarcas de seu tempo: "Dirigi-vos às mulheres; elas recebem prontamente, porque sấo ignorantes; elas espalham com facilidade, porque săo levianas; elas retêm por muito tempo, porque săo teimosas". Impenetráveis na dissimulaçăo, cruêis na vingança, constantes nos projetos, sem escrúpulos sobre os meios de vencer, animadas de um bdio profundo e secreto contra o despotismo do homem, parece que hâ entre elas uma conjura fácil de dominar, uma espécie de liga, tal como a que subsiste entre os sacerdotes de todas as naçסes. Elas conhecem seus artigos sem te-los comunicado umas às outras. Naturalmente curiosas, querem saber, seja para usar, seja para abusar, de tudo. Nos tempos de revoluçăo, a curiosidade as prostitui aos chefes de partido. Aquele que as adivinha ế seu inimigo implacável. Se as amais, elas vos perderăo, elas se perderăo a si mesmas; se cruzais seus intentos ambiciosos, elas têm no fundo do coraçăo o que o poeta colocou na boca de Roxane:

Apesar de todo meu amor, se neste dia

Ele náo me prender a si por um justo himeneu;

Se ousar me alegar uma lei odiosa;

Quando faço tudo por ele, se ele náo faz tudo por mim;

Deste tal momento, sem pensar se eu o amo,

Sem consultar enfim se eu mesma me perco,

Abandono o ingrato, e o deixo voltar

Ao estado infeliz de onde soube tirá-lo.

Racine, Bajazet, ato I, cena III.

Todas merecem ouvir o que um outro poeta, menos elegante, dirige a uma dentre elas:

Foi assim que, sempre presa de seus delinios,

Vossas semelhantes souberam sustentar seu império,

Vơs não amaste jamais, vosso coraçāo insolente

Tende bem menos ao amor do que a subjugar o

amante.

Que vos façam reinar e tudo vos parecerá justo;

Mas desprezarleis o amante mais augusto,

Se năo sacrificasse ao poder de vossos olhos

Sua honra, seu dever, a justiça e os deuses.

Elas simularắo a embriaguez da paixăo, se tiverem grande interesse em vos enganar; experimentâ-la-ăo, sem se esquecer de si. O momento em que estiverem inteiramente entregues a seu projeto será por vezes o momento mesmo de seu abandono. Elas se lludem melhor do que nós sobre o que thes apraz. O orgulho es mais o vício delas do que o nosso. Uma jovem samoieda dançava nua, com um punhal na măo. Parecia golpear-se com ele; mas esquivava-se aos golpes que ela mesma se desfechava com uma presteza tăo singular, que persuadira seus compatriotas que era um deus que a tornava invulnerável; $\theta$ ei-la pessoa sagrada. Alguns viajantes europeus assistiram a essa dança religiosa; e, embora plenamente convencidos de que a mulher năo passava de um saltimbanco muito destro, ela enganou seus olhos com a celeridade de seus movimentos. No dia seguinte, suplicaram-lhe que dançasse ainda uma vez. "Năo, disse-lhes, năo dançarei, o deus năo quer; e eu iria ferir-me." Insistiram. Os habitantes do pals uniram seus votos aos dos europeus. Ela dançou. Foi desmascarada. Ela se apercebeu do fato; e imediatamente ei-la estendida por terra, o punhal com que se armara mergulhado nos seus intestinos. "Eu bern que previra, dizia aos que a socorriam, que o deus năo queria, e que eu me feriria." $\mathrm{O}$ que me surpreende năo ế que ela tenha preferido a morte à vergonha, mas que se deixasse curar. E em nossos dias, nấo vimos uma dessas mulheres que representavam no suplicio a infância da Igreja, com os pés e as măos pregadas numa cruz, o flanco trespassado por uma lança, guardar o tom de seu papel em meio das convulsoes da dor, sob o suor frio que escorria de seus membros, com os olhos obscurecidos pelo vêu da morte ${ }^{(4)} e$, dirigindo-se ao diretor desse bando de fanáticos, dizer-the, năo com voz sofredora: "Meu pai, quero dormir", mas com uma voz infantil: "Papai, eu quero fazer naninha"? Para um homem, há cem mulheres capazes desta força e desta presença de esplrito. Essa mesma mulher, ou uma de suas companheiras, dizia ao jovem Dudoyer, que ela mirava ternamente, enquanto uma tenaz lhe arrancava os pregos que Ihe atravessavam os dois pés: "O deus a quem devemos o dom dos prodigios nem sempre nos concedeu o da santidade". A sra. de 


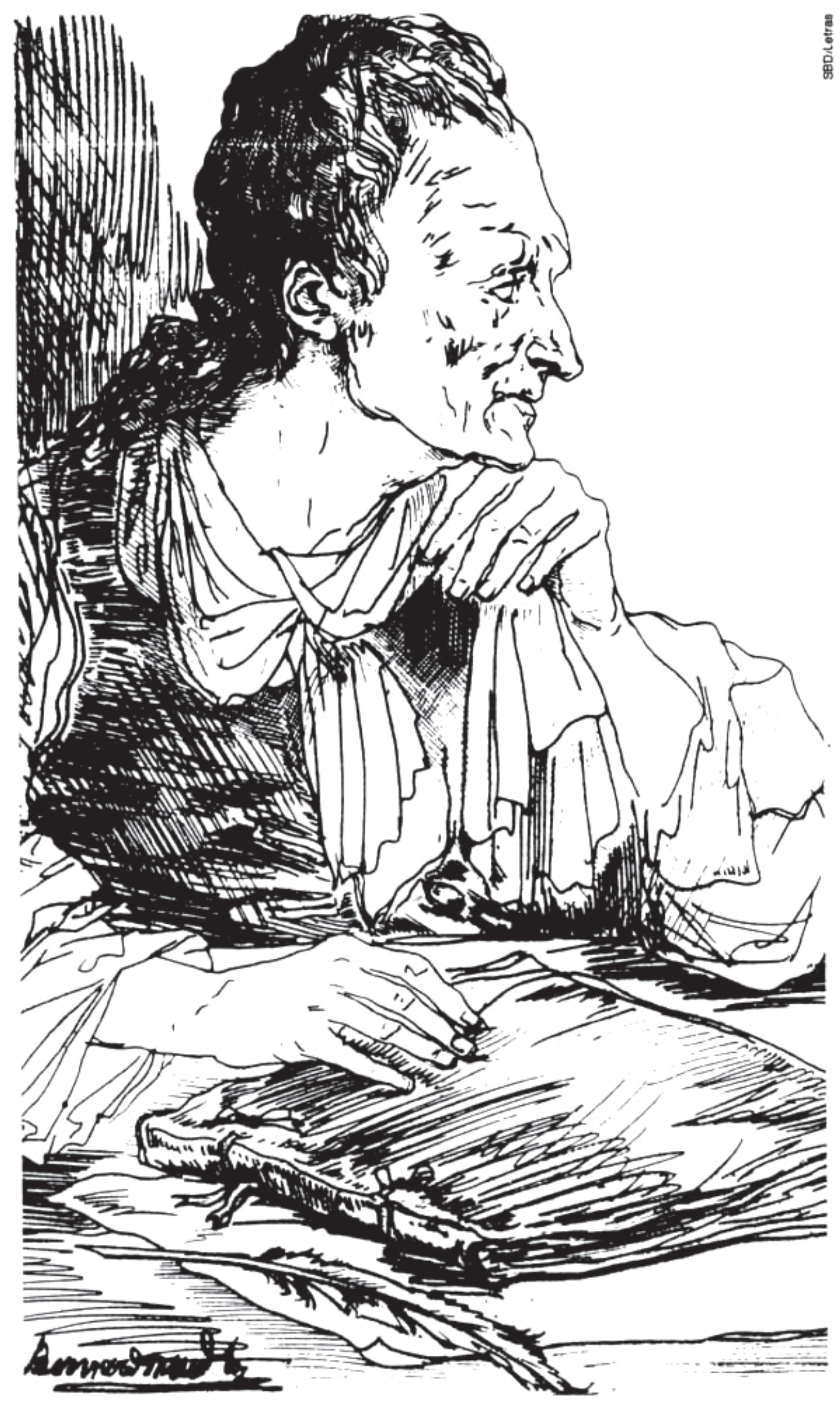

Denis Diderot; retrato de Bernard Naudin 
Maine confessou tudo. Imediatamente chora, rola por terra, brada: "Ahl minha pobre amante ficou loucal" Nåo esperai nada de semelhante de um homem. A mulher traz dentro de si mesma um orgão suscetfvel de espasmos terrfveis, que dispōe dela, e que suscita em sua imaginaçăo fantasmas de toda espécie. É no delfrio histérico que ela volta atrás ao passado, que ela se lança para o futuro, que todos os tempos lhe săo presentes. É do órgăo próprio a seu sexo que partem todas as suas idêias extraordinårias. A mulher, histêrica na mocidade, faz-se devota na idade avançada; a mulher a quem resta alguma energia na idade avançada era histérica na juventude. Sua cabeça fala ainda a linguagem de seus sentidos quando estes se acham mudos. Nada é mais contiguo que o êxtase, a visăo, a profecia, a revelaçăo, a poesia fogosa e o histerismo. Quando a prussiana Karsch ergue o olhar para o céu inflamado de relâmpagos, ela về Deus na nuvem; ela o về sacudir com uma fralda de sua veste preta raios que văo procurar a cabeça do impio; ela vê a cabeça do impio. Entretanto, a reclusa em sua cela sente elevar-se nos ares; sua alma se espalha no seio da Divindade; sua essência se mistura à essência divina; ela agoniza; seu peito se ergue e se abaixa com rapidez; seus companheiros, reunidos em torno dela, cortam os laços de seu vestuârio que a aperta. A noite vem; ela ouve os coros celestes; sua voz se une a seus concertos. Em seguida ela volta a descer à terra; ela fala de alegrias inefáveis; escutam-na; ela está convencida; persuadida. A mulher dominada pelo histerismo experimenta năo sei o que de infernal ou de celeste. As vezes, ela me faz estremecer. É no furor da besta feroz que faz parte dela mesma, que eu a vi, que eu a ouvi. Como ela sential, como se exprimia! O que ela dizia năo era coisa de mortal. A sra. Guyon(5) tem, em seu livro das Torrentes, linhas de uma eloquência de que năo há modelos. Foi Santa Tereza quem disse dos demônios: Como são infelizes!, eles não amam! O quietismo ê a hipocrisia do homem perverso, e a verdadeira religiăo da mulher terna. Houve entretanto um homem de uma honestidade de caráter e de uma simplicidade de costumes tăo raras, que uma mulher amável pơde, sem conseqũências, esquecer-se ao seu lado e desafogar-se em Deus; mas esse homem era único; ele chamava-se Fênelon. É uma mulher que passeava nas ruas de Alexandria, com os pés nus, a cabeça desgrenhada, uma tocha numa das måos, um gomil na outra, e que dizia: "Quero queimar o céu com esta tocha, e extinguir o inferno com esta água, a fim de que o homem năo ame seu Deus senăo por ele mesmo". Este papel só assenta a uma mulher. Mas essa imaginaçăo fogosa, esse espfrito que se julgaria incoerclvel, basta uma palavra para abate-lo. Um médico diz às mulheres de Bordeaux, atormentadas por vapores pavorosos, que elas estăo ameaçadas de epilepsia; e ei-las curadas. Um médico brande um ferro candente diante dos olhos de um bando de jovens epilépticas; e ei-las curadas. Os magistrados de Mileto declararam que a primeira mulher a se matar será exposta nua na praça pública; e eis as milesianas reconciliadas com a vida. As mulheres estâo sujeitas a uma ferocidade epidêmica. $O$ exemplo de uma so arrasta uma multidăo. Sర a primeira é criminosa; as outras săo doentes. $\delta$, mulheres, sois crianças bem extraordinárias! Com um pouco de dor e de sensibilidade (eh, sr. Thomas, por que năo vos abandonais a estas duas qualidades, que năo vos são estranhas?) que enternecimento năo nos terfeis inspirado, mostrando-nos as mulheres submetidas como nós às enfermidades da infancia, mais coagidas e mais negligenciadas em sua educaçăo, abandonadas aos mesmos caprichos da sorte, com uma alma mais móvel, com órgăos mais delicados e sem nada dessa firmeza natural ou adquirida que nos prepara para isso; reduzidas ao silêncio na idade ađulta, sujeitas a um mal-estar que as dispōe a tornarem-se esposas e māes: entăo tristes, inquietas, melancólicas, ao lado dos pais alarmados, năo ső com a saúde e a vida da filha, mas ainda com seu caráter: pois é nesse instante crftico que uma jovem se torna o que ela continuarâ sendo toda a sua vida, penetrante ou estúpida, triste ou alegre, séna ou leviana, boa ou mâ, a esperança de sua mâe realizada ou enganada. Durante uma longa série de anos, cada lua trar-lhe-â de volta o mesmo mal-estar. O momento que as libertará do despotismo dos pais é chegado; sua imaginaçăo abre-se para um futuro cheio de quimeras; seu coraçăo nada em secreta alegria. Alegra-te bastante, desventurada criatura; o tempo teria sem cessar enfraquecido a tirania que deixas; o tempo aumentará sem cessar a tirania pela qual vais passar. Escolhem-lhe um esposo. Ela se torna măe. O estado de gravidez é penoso para quase todas as mulheres. É em meio de dores, com perigo de sua vida, às custas de seus encantos, e amiúde em detrimento de sua saúde, que elas dâo à luz os filhos. O primeiro domicllio da criança e os dois reservatórios de sua comida, os órgăos que caracterizam o sexo, estăo expostos a duas moléstias incuráveis. Năo hấ talvez alegria comparável à da mãe que về seu primogênito; mas esse momento terá um preço bem caro. $O$ pai descarrega o cuidado com os meninos sobre um mercenário; a măe fica encarregada da guarda de suas filhas. A idade avança; a beleza passa; chegam os anos do abandono, do mau humor e do tédio. É pelo mal-estar que a natureza as dispôs a tornarem-se măes; é por uma longa e perigosa doença que ela lhes subtrai o poder de sê-lo. O que é entăo uma mulher? Negligenciada pelo esposo, desamparada pelos filhos, ninguêm na sociedade, a devoçăo constitui seu único e derra- 
deiro recurso. Em quase todos os palses, a crueldade das leis civis reuniu-se, contra as mulheres, à crueldade da natureza. Elas foram tratadas como crianças imbecis. Năo há espécie de vexames que, nos povos policiados, o homem năo possa exercer impunemente contra a mulher. A única represália que depende dela é seguida da perturbaçăo doméstica, e punida com um menosprezo mais ou menos acentuado, conforme a naçăo tenha mais ou menos hábitos de sociedade. Năo hâ espêcie de vexames que o selvagem năo exerça contra sua mulher. A mulher, infeliz nas cidades, é mais infeliz ainda no fundo das florestas. Escutai o discurso de uma lndia das margens do Orenoco; e escutai-o, se o podeis, sem ficar emocionado. O missionário jesulta Gumilla repreendia-a por haver dado a morte a uma filha que ela concebera, cortando-lhe o umbigo muito curto: "Prouvesse a Deus, padre, disse-Ihe ela, prouvesse a Deus que no momento em que minha mãe me pôs no mundo, ela tivesse tido bastante compaixão e amor para poupar à sua criança tudo o que suportei e tudo o que suportarei até o fim de meus dias! Se minha mãe me houvesse sufocado ao nascer, eu estaria morta; mas năo teria sentido a morte, e teria escapado â mais infeliz das condiçōes. Quanto sofril, e quem sabe quanto me resta a sofrer atê que eu morra? Imagina só, padre, as penas que estāo reservadas a uma india entre esses Indios. Eles nos acompanham aos campos com seus arcos e suas flechas. Nós vamos, carregadas com uma criança que pende de nossas mamas e outra que levamos numa cesta. Eles vấo matar um pássaro, ou apanhar um peixe. Nos cavamos a terra, nós; e depois de termos suportado toda a fadiga do cultivo, suportamos toda a fadiga da colheita. Eles regressam à tarde sem nenhuma carga; nós, nos lhes trazemos ralzes para a sua comida, e milho para a sua bebida. De retorno à sua casa, eles văo entreter-se com os amigos; nós, nós vamos procurar lenha e água para preparar-lhes a ceia. Terminam de comer, adormecem; nos, nos passamos quase a noite toda a moer o milho e a fazerIhes a chica, e qual é a recompensa de nossas viglias? Eles bebem a chica, embriagam-se; e quando estăo bebados, nos arrastam pelos cabelos e nos pisam com os pés. Ah!, padre, prouvesse a Deus que minha măe me houvesse sufocado quando nasci. Tu sabes por ti mesmo se nossas queixas săo justas. Isso que estou te dizendo, tu o vês todos os dias. Nossa maior desgraça, porém, tu năo poderias conhecer. É triste para a pobre India servir o marido como urna escrava, nos campos prostrada de suores, e na habitaçăo privada de repouso; mas é terrfvel vê-lo, ao cabo de vinte anos, tomar outra mulher mais jovem, que năo tem nenhum jufzo. Ele se lhe apega. Ela nos bate, bate em nossos filhos, ela nos comanda, nos trata como servas; e ao menor murmúrio que nos escapa, um ramo de árvore levantado... Ah!, padre, como queres que suportemos tal estado? O que há de melhor a fazer para uma india, do que subtrair sua criança a uma servidăo mil vezes pior do que a morte? Prouvesse a Deus, padre, eu te repito, que minha măe me tivesse amado suficientemente para me enterrar quando nasci! Meu coraçăo năo teria tanto para sofrer, nem meus olhos tanto para chorarl".

Mulheres, como eu vos lastimo! Não há senăo uma reparaçăo para vossos males; e fosse eu legislador, talvez a terleis obtido. Libertadas de toda servidăo, serfeis sagradas em qualquer lugar onde aparecêsseis. Quando se escreve a respeito das mulheres, cumpre molhar a pena no arco-fris e jogar sobre a linha o pó das asas de borboleta; como o căozinho do peregrino, cada vez que se sacode a pata, é preciso que dela tombem pérolas; e elas năo tombam da do sr. Thomas. Năo basta falar das mulheres, e de falar bem delas, sr. Thomas, fazei ainda com que eu as veja. Suspendei-as sob meus olhos, como outros tantos termômetros das menores vicissitudes dos costumes e das práticas. Fixai, com a maior justiça e imparcialidade que puderdes, as prerrogativas do homem e da mulher; mas năo esquecei que, por falta de reflexăo e de princlpios, nada penetra até uma certa profundidade de convicçăo no entendimento das mulheres; que as idéias de justiça, de virtude, de vício, de bondade, de malignidade, nadam à superfície de sua alma; que elas conservaram o amor próprio e o interesse pessoal com toda a energia de natureza; $\theta$ que, mais civilizadas que nos por fora, permaneceram verdadeiras selvagens por dentro, todas maquiavélicas, da maior à menor. O símbolo das mulheres em geral é o do Apocalipse, em cuja fronte estå escrito: "mistério". Onde há uma parede de bronze para nơs, năo hâ senăo uma teia de aranha para elas. Alguém perguntou se as mulheres eram feitas para a amizade. Hâ mulheres que săo homens, e homens que săo mulheres; e confesso que nunca faria amigo meu um homem-mulher. Se possulmos mais razăo que a mulher, ela possui mais instinto que nós. A única coisa que se lhes ensinou es usar bem a folha de figueira que receberam de sua primeira avoenga. Tudo o que se Ihes disse e repetiu dezoito a dezenove anos seguidos reduz-se a isso: Minha filha, tomai cuidado com vossa folha de figueira; vossa folha de figueira vai bem, vossa folha de figueira vai mal. Em uma naçăo galante, a coisa menos sentida ê o valor de uma declaraçăo. O homem e a mulher vêem af apenas uma troca de gozos. Entretanto, o que significa a frase tăo levianamente pronunciada, tăo frivolamente interpretada: $E u$ vos amol significa realmente: "Se quiserdes me sacrificar vossa inocência e vossos bons costumes; perder o respeito que dedicais a vơs mesma, e que 
Diderot, por Chardin (Museu Conde, Chantilly)

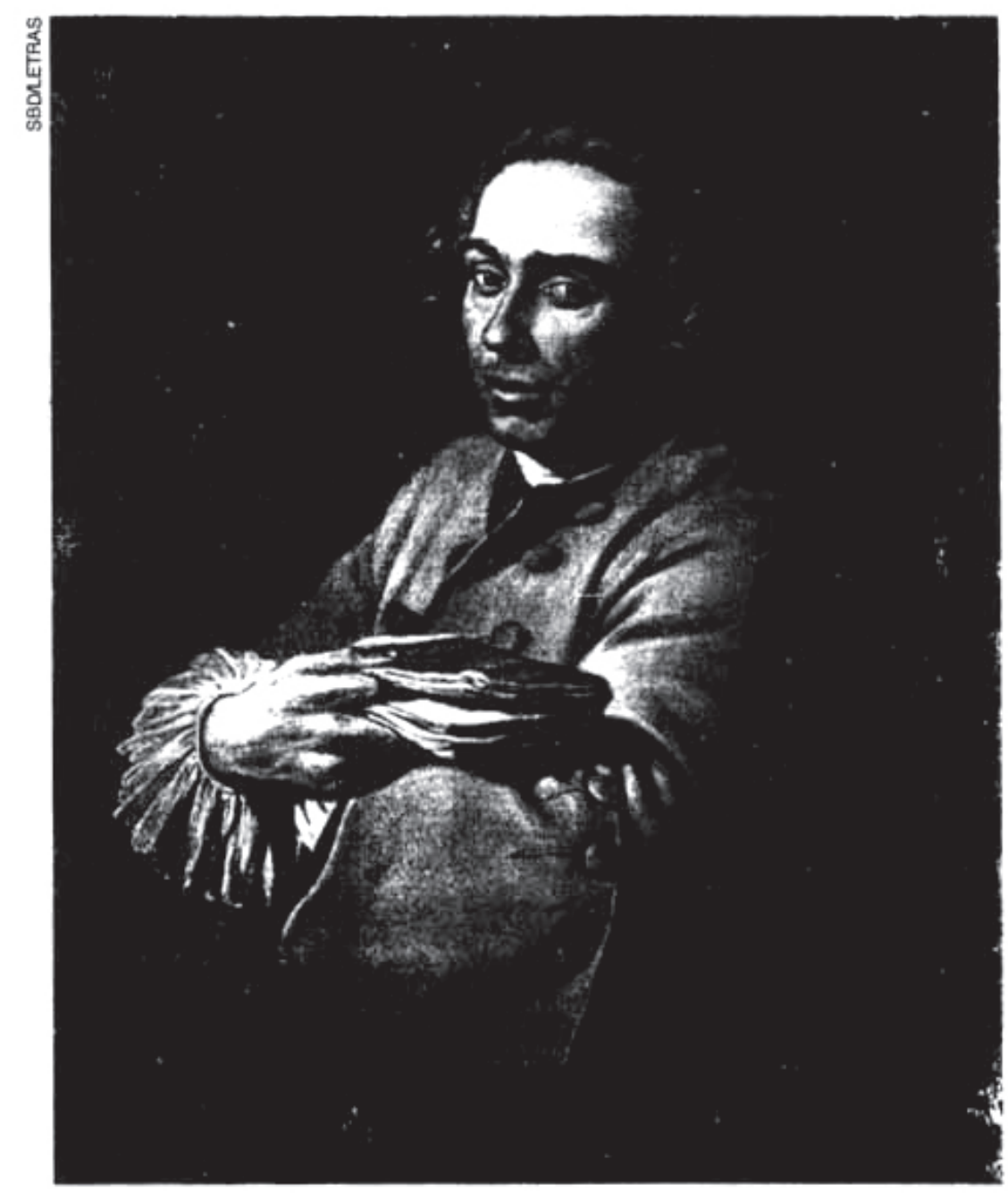

obtendes dos outros; andar com os olhos baixos na sociedade, ao menos até que, pelo hábito da libertinagem, tenhais adquirido o seu descaramento; renunciar a todo estado honesto; matar vossos pais de dor, e me conceder um momento de prazer, eu vos ficaria verdadeiramente agradecido". Măes, lede essas linhas a vossas filhas: ê, em resumo, o comentário de todos os discursos lisonjeadores que hăo de Ihes ser dirigidos; e podeis preveni-las a este respeito desde muito cedo. Atribuiu-se tanto importância à galanteria, que parece năo restar nenhuma virtude àquela que deu esse passo. É como a falsa devota e o mau sacerdote, em quem a incredulidade é quase o selo da depravaçăo. Aposs haver cometido o grande crime, năo podem sentir horror de nada. Enquanto nós lemos nos livros, elas lêem no grande livro do mundo. Por isso a ignorância delas as dispōe a receber prontamente a verdade, quando esta lhes é mostrada. Nenhuma autoridade as subjugou; ao passo que a verdade encontra à entrada de nossos crânios um Platăo, um Aristóteles, um Epicuro, um Zenăo, de sentinela, e armados de piques para repeli-la. Elas săo raramente sistemáticas, sempre ficam ao ditado do momento. Thomas nẵo diz uma palayra sobre as vantagens do convivio com as mulheres para um homem de letras; e é um ingrato. Como a alma das mulheres năo ê mais honesta do que a nossa, mas a decência năo lhes permite explicar-se com a nossa franqueza, elas criaram para si uma ramagem delicada, por meio da qual se diz honestamente tudo o que se quer quando o assobio chama ao viveiro delas. Ou as mulheres se calam, ou muitas vezes têm o ar de năo ousar dizer o que dizem. Percebe-se facilimente que Jean-Jacques perdeu muitos momentos aos joelhos das mulheres, e que Marmontel empregou muitos outros em seus braços. Suspeitar-se-ia de bom grado que Thomas e d'Alembert foram bem-comportados demais. Elas nos acostumam ainda a por graça e clareza nas matêrias mais secas e mais espinhosas. A gente lhes dirige incessantemente a palavra; a gente quer ser ouvido por elas; teme fatigḱ-las ou entediá-las; e assume uma facilidade particular de exprimir-se, que passa da conversaçăo ao estilo. Quando elas têm gênio, creio que a sua marca nelas ế mais original do que em nós. 